certain to be seen when the net is not at hand. How, under such circumstances, is the butterfly to be caught? I reply, wait till it settles, and then pick it up. Perhaps most of your readers will reply "Absurd, no butterfly will sit to be caught in that way." Try and see. Whenever the butterfly settles you may walk quickly up to within $\mathrm{a}^{2}$ short distance from it; the distance will depend on the nature of the butterfly. Arrived at a short dis. tance from the butterfly, the motion must now be slow and even, and as the hand is slowly and steadily advanced towards the butterfly, it will take little or no notice of it, and may be easily picked up with the fingers. In Italy this spring I picked up in this manner both varieties of swallow-tails, as many as five when walking one afternoon. I have also caught in this way, whites, red admirals, painted ladies, peacocks, and many other smaller varieties, This manner of catching butterflies does look sus. piciously like the old story of catching birds by putting salt on their tails. Before anyone conjemns it, I ask him to give it a fair trial, and $I$ have no doubt he will be astonished at his success. The only thing to guard against is any jerkiness in your motions. All your motions when near the butterfly must be slow and regular. Perhaps the butterfly may not sit long enough for you to approach it by such slow motions. If the butterfly does rise take care not to change your slow and steady motions, and it will take no notice of you, and will often settle again within a few inches of your hand. Ofien the butterfly takes no notice of you ; at other times it seems sensible of danger, bue generally contents itself by folding its wings as close as possible, as if to escape notice. When the wings are in this position the butterfly is caught with least clamage to its plumage. But in some cases the wings are open. When that is the case 1 have sometimes folded the wings before picking them up, in order to save the plumage, so tame are they under this treatment. At first I thought it was necessary to approach the butterfly from behind, and keep out of sight as much as possible, but this I find, thoitgh an advantage, is not essential. Of course I do not advocate this plan of catching butterflies when a net can be got, as it is much slower and not so certain. Yet it has its advantages. You get the butterfly without breaking its wings or ruffing a feather, and if not a good specimen you can let it away unhurt.

J.A.

\section{ERNEST T. CHAPMAN}

TM. E. T. CHAPMAN has met his death by an exII plosion in his laboratory at Rubeland in the Hartz. A letter containing this sad news has the following particulars :-

"As you are probably aware, Mr. Chapman's work was always in the laboratory, and it was there on the 25 th inst. (June) that the accident occurred. On the morning of that day Mr. Chapman had a conversation with the gentlemen here, and shortly after this, at II A.M., the bomb-proof building in which he was with three workmen exploded with a tremendous crash. Mr. Chapman may perhaps have informed you that latterly he has been chiefly engaged with the production of nitric methylxther, with which he has been making various experiments, and we cannot explain the catastrophe otherwise than that he was not thoroughly aware of the great explosibility of this substance. The workmen present having also all perished, it is unfortunately not possible to obtain any details. The force of the explosion was so tremenclous that all the surrounding buildings have been more or less injured, and about ten people seriously wounded."

The substance I presume was nitrate of methyl. If so, this lamentable accident furnishes another proof of the treacherous nature of explosives which, like nitro-glycerine and gun-cotton, contain hydrogen and carbon associated with nitrogen oxides.

Mr. Chapman was only in his twenty-seventh year when his career was thus prematurely closed. A pupil of Hoffmann and Kolbe, he was a prolific author of original researches in organic chemistry. Perhaps the best known of Mr. Chapman's researches is his study of limited oxidation. This process, in his hands and those of others, furnished chemists with a valuable method of chemical diagnosis. The little work on the Analysis of Potable Waters, by Mr. Chapman and Mr. Wanklyn, is a well-known work of reference on this important subject.

Mr. Chapman was an enthusiastic worker. His manipulative skill was of a high order, and his acquaintance with organic chemistry very extensive, his researches in this branch of science being very numerous. If he had lived, and had an opportunity of continuous scientific work, it is impossible to doubt that he would have contributed his quota towards rescuing our country from the too just reproach of rapidly becoming more and more sterile in chemical discoveries.

His intimate friends esteemed him highly, for he was a man of varied culture and singular conversational power. It was always a matter of regret to all true friends of science that a man of such proved ability and promise should have been compelled in a manner to banish himself in order to gain a livelihood. His letters show that even in the remote place of his exile his brain was busy with chemical and physical questions. $\mathrm{He}$ must have been killed instantly, and therefore without pain. And certainly as a brave and loyal soldier of science slain on the battle-field of the laboratory, his death, like his life, showed his unwearied devotion to science. We can ill afford to lose such men.

FREDERICK GUTHRIE

\section{DR. WILLIAM STIMPSON*}

DED, at Ilchester, Maryland, May 26, of consumption, Dr. William Stimpson, Secretary of the Chicago Academy of Sciences, in the forty-second year of his age.

The announcement of the death of Dr. Stimpson will be received with profound regret, not only by a wide circle of friends here, but throughout the country. Science has lost an assiduous cultivator, the value of whose labours was recognised in both hemispheres.

For the second time in the course of a few years the Chicago Academy is called upon to mourn the loss of an accomplished secretary. Under Dr. Stimpson's energetic supervision, the collections gathered within its walls at the time of the great fire, in magnitude and importance ranked fifth in the United States, and so admirable were his arrangements that they were flowing in from every quarter of the world. .Their total destruction on the morning of the gth of October last was a terrible blow to the secretary. His private losses, too, were beyond computation, embracing as they did a choice scientific library, gathered at different intervals - many of the volumes being out of print, and many of them being presentation copies from the authors-and also all his manuscripts, including those of the Government Japan Expedition, of which he was the naturalist, which were written out for publication, and were copiously illustrated by drawings, many of which were engraved. Thus, in an hour, perished the results of twenty years' unremitting scientific labour.

To show the high estimation in which Dr. Stimpson was held by men engaged in kindred pursuits, it may be stated that, at the instigation of Agassiz, the results of the deep-sea dredgings of the United States Coast Survey were passed over to him for description-a task calling for the most exact and extensive knowledge.

After the terrible calamity to which we have referred, Dr. Stimpson remarked that he had not the heart to attempt to enter upon his life-worik again, but would devote all his energies to the restoration of the Academy. 